\title{
Women and Bleeding Disorders
}
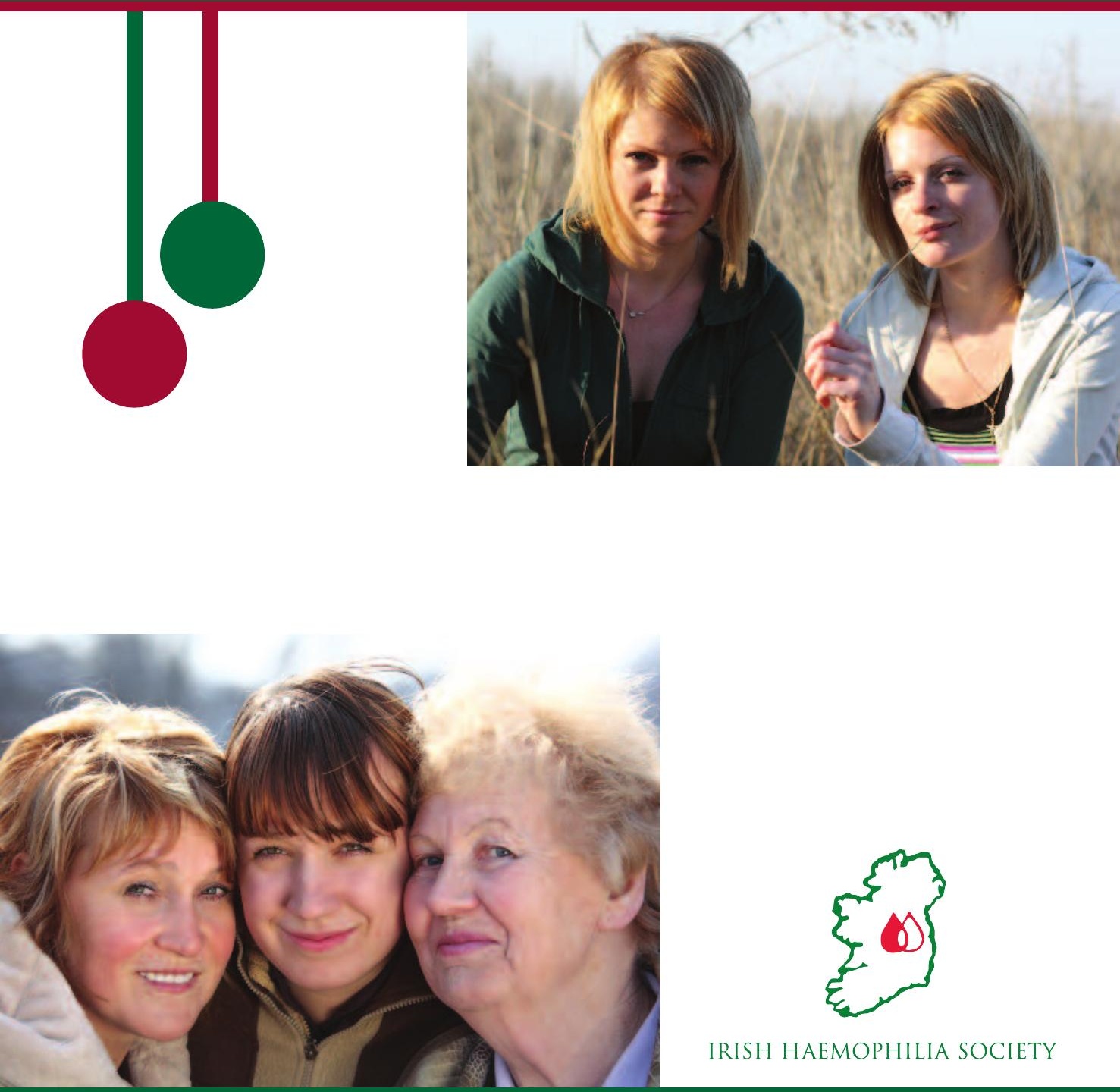

IRISH HAEMOPHILIA SOCIETY 


\section{Introduction}

The popular and public perception of haemophilia is of an exclusively male inherited bleeding disorder. Historically, this perception was most famously seen as reality with the fact that Queen Victoria was known to be a carrier of haemophilia, and via her, haemophilia was found in the royal families of Great Britian, Spain and Russia. The most famous person with haemophilia was the Tzarevich Alexis who along with his parents and sisters was killed in 1918 in the immediate aftermath of the Bolshevik revolution in Russia.

It is certainly the case that classic haemophilia $A$ and $B$ are found primarily in males, wheras the gene is carried by females. This is far from the complete story. Women rarely suffer from severe haemophilia either via genetic inheritance or mutation or via a process known as lyonization of the chromosome which is explained in this guide. However, it is quite common for carriers of haemophilia to have relatively low factor levels which categorise them as having mild haemophilia. There are 54 females currently diagnosed in Ireland with haemophilia $A$ and 44 with haemophilia B. The vast majority of these are carriers with Factor VIII or FIX levels which put them in the category of mild haemophilia. Thankfully, they will not suffer from spontaneous bleeds into joints or muscles so characteristic of severe haemophilia, but they may require factor replacement therapy following trauma, surgery or childbirth and menstruation can pose problems beyond the normal range of the female experience. Von Willebrands Disease is more from a gender perspective, affecting both sexes. Indeed of the 918 persons in Ireland known to have Von Willebrands, 537 are female. Again, many will not require therapy on a regular basis but for females, menstruation is often characterised by menorrhagia, pregnancy by additional concern about bleeding and contraception more often a therapeutic requirement than a life choice. In the past, women with undiagnosed bleeding disorders often faced long delays before adequate treatment, frequent menorrhagia, and all too often unnecessary hysterectomy. Concerns now can include menstrual problems, pregnancy carrier status and inheritance, menopause and treatment. Knowing about your particular bleeding disorder and its severity, symptoms and treatment is vital. Registering at the NCHCD and getting the expert medical advice and assistance needed is the path to helping you cope with a diagnosis of a bleeding disorder or carrier status.

This guide covers the basics of how blood clots, the inheritance of bleeding disorders and gives an introduction to haemophilia and Von Willebrands Disease. A separate publication from the Irish Haemophilia Society is available on the rarer bleeding disorders. This guide also covers potential consequences of a bleeding disorder including menstrual problems, contraceptive therapy and hysterectomy. Life events including pregnancy and menopause are discussed in the context of a bleeding disorder. The psychosocial aspects are explored. Knowledge is power and we hope that this guide will help to empower you to live positively with your bleeding disorder. Be assured that the Irish Haemophilia Society at all times stands ready to help you with information, advice and assistance. Our website www.haemophilia.ie is the source of a lot of useful information. Our regular magazines can be downloaded free of charge and we are always more than happy to provide copies of publications or information materials. We also organise, on a regular basis, meetings and conferences for members which routinely cover the topics relevant to women with bleeding disorders, which allows them access to expert speakers in a supportive and collegial atmosphere. We hope that you will find this guide a useful resource. 


\section{Contents}

How does blood clot?

Page

How are Bleeding Disorders inherited?

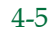

Autosomal inheritance pattern

Sex-linked inheritance pattern

Bleeding Disorders

Von Willebrands Disease

Platelet Function Disorders

Other clotting factor deficiencies 11

Haemophilia and Symptomatic Carriers

Haemophilia

Symptomatic Carriers

Tests

Genetic analysis \& testing

Psychosocial issues

Gynaecological Problems

Menorrhagia

Management of Menorrhagia in Women with Bleeding Disorders

Treatment

Haemostatic therapy

Surgical treatment

Other gynaecological conditions

Dysmenorrhoea

Haemorrhagic ovarian cysts

Endometriosis and other gynaecological conditions 20

Menopause

Acute adolescent menorrhagia $\quad 21$

Other types of bleeding

Treatment Options for Other Types of Bleeding 21

$\begin{array}{ll}\text { Tranexamic acid } & 17\end{array}$

DDAVP (Desmopressin) 17

Coagulation Factor Concentrate Replacement Therapy $\quad 17$

Fibrin Glue $\quad 21$

Pregnancy in Women with Bleeding Disorders $22-29$

Preconception counselling $\quad 22$

Prenatal diagnosis (PND) 22

Foetal sex determination $\quad 22-23$

Pre-implantation genetic diagnosis $\quad 24$

Antenatal Management 24

Miscarriage/ Pregnancy Complications 25

Management of labour and delivery 25-26

Postpartum management $\quad 27-28$

Breast Feeding $\quad 29$

Glossary 30-31 


\section{How does blood clot?}

Blood is carried throughout the body in a network of blood vessels. When tissues are injured, damage to a blood vessel may result in leakage of blood through holes in a vessel wall which may be internal or external. When the blood vessel wall breaks, the components responsible for clotting or coagulation, come together to form a plug at the break.

There are four steps involved in forming a plug (Figure 1):

\section{Step 1:}

The blood vessel is damaged.

\section{Step 2:}

The blood vessel contracts (becomes narrower) to reduce the blood flow to the damaged area and to allow the components responsible for coagulation to come into contact with the damaged tissue.

\section{Step 3:}

\section{Platelet adhesion}

Platelets, which are very tiny cell fragments in the blood, stick to the walls of damaged vessels and spread out.

\section{Platelet activation}

These platelets then produce chemical signals that activate other nearby platelets.

\section{Platelet aggregation}

Activated platelets clump together at the site of the damage in order to form a platelet plug which blocks the break.

\section{Von Willebrand factor (vWF)}

vWF is a protein which helps platelets to stick to the damaged blood vessel wall and also carries factor VIII (another important protein in blood clotting) through the bloodstream. When there is not enough vWF in the blood or when it does not work the way it should the blood takes longer to clot.

\section{Step 4:}

The surface of activated platelets forms a base on which blood coagulation can take place. The coagulation factors (or coagulation proteins) circulating in the blood are activated at the surface of the platelets to form a fibrin clot which looks something like a mesh. 
Figure 1:

Forming a Clot

1. Bleeding starts

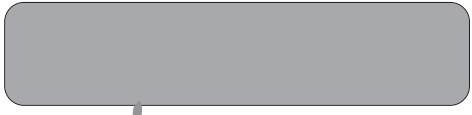

2. Vessels constrict

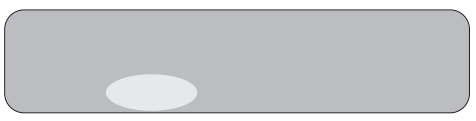

3. Platelet plug

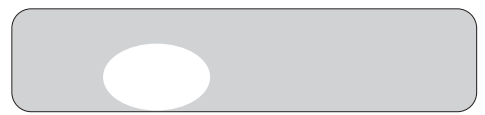

4. Flbrin clot

Coagulation factors (Factors I, II, V, VII, VIII, IX, X, XI and XII - Please note that coagulation factors are conventionally described in roman numerals) are triggered in a domino effect that is called the coagulation cascade. When a factor (domino) is missing or reduced then the cascade does not work effectively to repair the damaged vessel (Figure 2).

Figure 2:

Domino Effect of Clotting Cascade

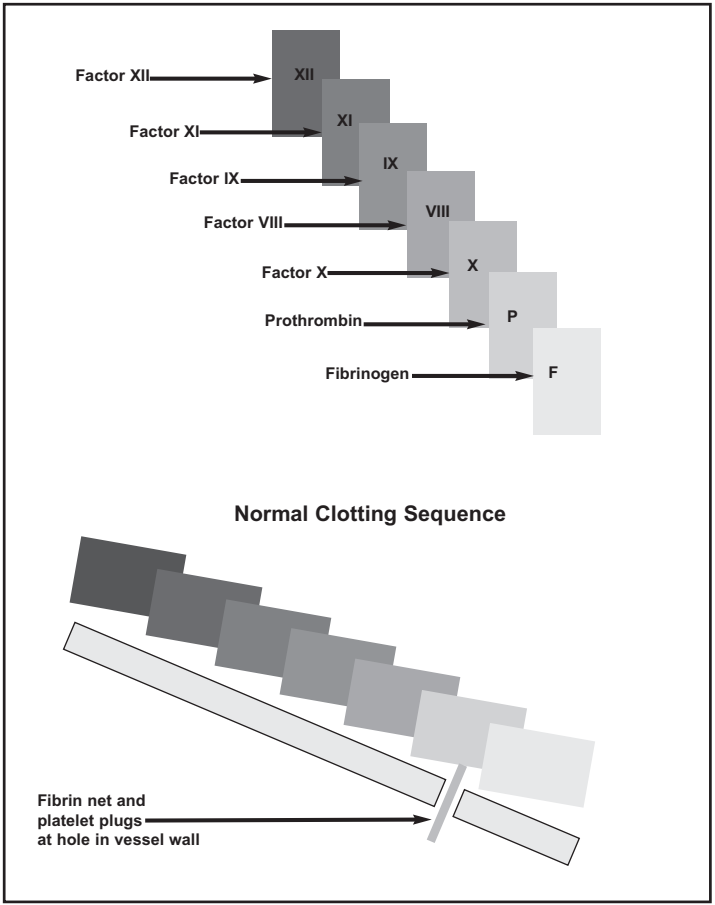




\section{How are Bleeding Disorders inherited?}

Inherited bleeding disorders are passed from parent to child at the time of conception. Each cell in the body has 23 pairs of chromosomes*. One of each pair is inherited from each parent. There are 22 matching pairs and one odd pair called the sex chromosomes - the $\mathrm{X}$ and the $\mathrm{Y}$ chromosome. These determine the sex of the individual. Females $(\mathrm{XX})$ have two $\mathrm{X}$ chromosomes. One $\mathrm{X}$ chromosome is inherited from the mother and one $X$ chromosome is inherited from the father. Males (XY) have one $X$ chromosome and one $Y$ chromosome. Males must inherit the $Y$ chromosome from the father and the $X$ chromosome from the mother.

\section{*Chromosomes:}

A chromosome is a long chain of chemicals known as DNA. DNA is arranged into units called genes. Genes determine such things as the colour of a person's eyes.

\section{Bleeding disorders are inherited by one of two patterns of inheritance}

\section{Autosomal inheritance}

\section{Sex linked inheritance}

\section{Autosomal inheritance pattern}

When the defective gene that causes a bleeding disorder is on a chromosome which does not decide the sex of the child it means the bleeding disorder is inherited in an autosomal manner. Bleeding disorders inherited in an autosomal manner affect females as well as males. The majority of bleeding disorders have autosomal inheritance patterns, for example deficiencies of Factors I, II, V, VII, X, XI, XII, XIII, von Willebrand's disease and some platelet function disorders. There are two types of autosomal inheritance patterns: autosomal recessive and autosomal dominant.

Autosomal dominant means that only one defective gene, from one of the child's parents, is required in order for the disorder to affect the child.

Autosomal recessive means that two defective genes, one from each parent, are required in order for the disorder to affect the child. Both parents must therefore be carriers.

A carrier of an autosomal disorder is someone who carries the defective gene without being affected by the disorder. The carrier of a factor deficiency may have a factor level just below, or at the lower limit of, the normal range.

A summary of the autosomal pattern of inheritance is shown in Figure 1-3 
Autosomal recessive

Figure 1 shows what can happen when both parents are carriers. There is one chance in four that the child will have normal factor levels, one chance in four that it will have the specific factor deficiency, and there are two chances in four that the child will be a carrier. Figure 1: Both parents are carriers of the specific factor deficiency

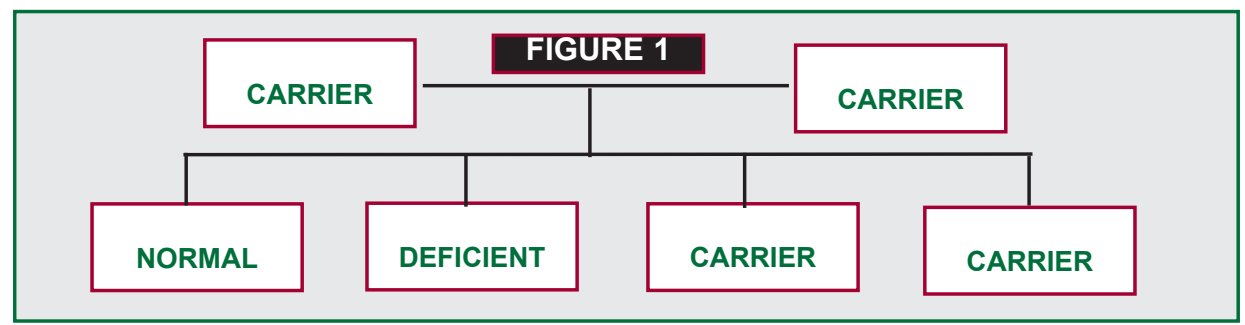

Figure 2 shows what can happen when one of the parents has the specific factor deficiency and the other has normal factor levels. All their children will be carriers of the specific factor deficiency. Figure 2: One parent has the specific factor deficiency deficiency

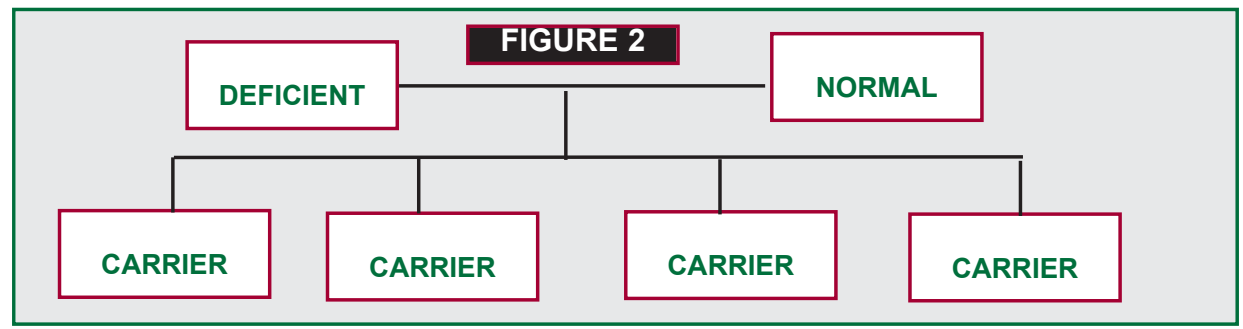

Figure 3 shows what can happen when one of the parents is a carrier of the specific factor deficiency and the other is normal. There are two chances in four that the child will be a carrier and two chances in four that it will be normal. Figure 3: One parent is a carrier

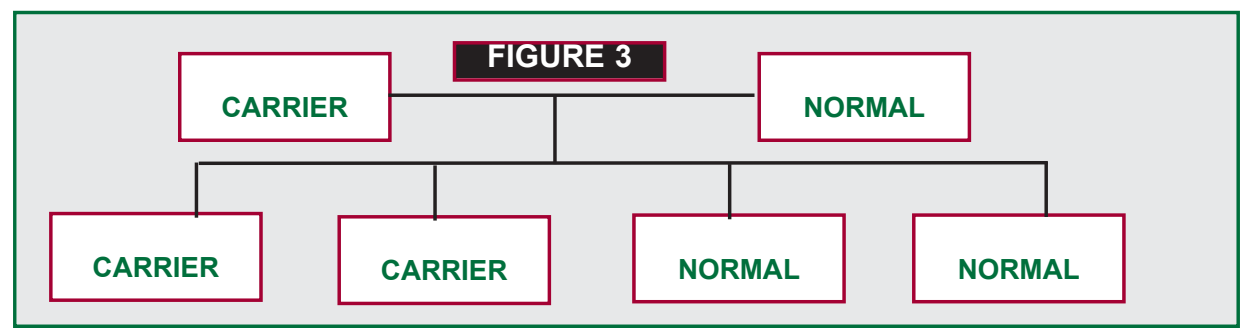




\section{Sex-linked inheritance pattern}

When the defective gene that causes a factor deficiency is on the chromosome that does decide the sex of a child, inheritance is said to be sex linked. The factor VIII and IX genes are on the X chromosome so Haemophilia A (factor VIII deficiency) and Haemophilia B (factor IX deficiency) are inherited in a sex linked manner.
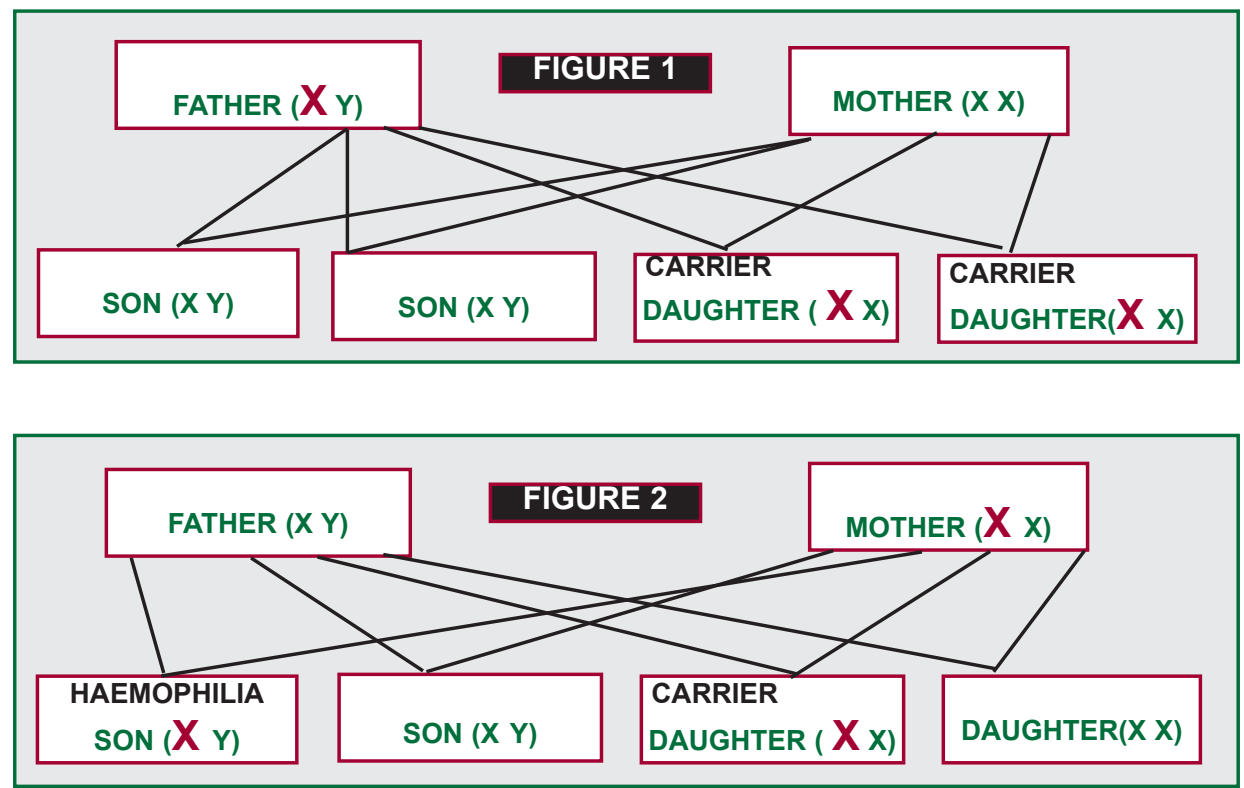

\section{A father with haemophilia (Figure 1)}

The sons of a father with haemophilia inherit his Y chromosome and therefore cannot inherit haemophilia or be "carriers" of haemophilia. However, all of the daughters of a man with haemophilia inherit his X chromosome and carry the haemophilia gene. They are "obligate carriers" as they must inherit an X chromosome from their father.

\section{A carrier of haemophilia (Figure 2)}

A carrier has one normal and one abnormal X chromosome. Each son will have a $50 \%$ chance of having haemophilia. As men only inherit one $X$ chromosome they will be affected by haemophilia and therefore are not referred to as carriers. Each daughter will have a 50\% chance of being a carrier. There are two types of carriers: obligate carriers and possible carriers. Obligate carriers are women who definitely carry the affected gene. Possible carriers are women who may or may not carry the affected gene. 


\section{Obligate carriers are:}

- All daughters of a man with haemophilia.

- Mothers of one son with haemophilia and at least one other family member with haemophilia (brother, maternal grandfather, uncle, nephew, or cousin).

- Mothers of one son with haemophilia and a family member who is a carrier of the haemophilia gene (mother, sister, maternal grandmother, aunt, niece, or cousin).

- Mothers of two or more sons with haemophilia.

\section{Possible carriers are:}

- All daughters of a carrier.

- Mothers of one son with haemophilia who have no other family members who either have or are carriers of haemophilia.

- Sisters, mothers, maternal grandmothers, aunts, nieces, and female cousins of carriers.

\section{Lyonization}

Lyonization is when an $\mathrm{X}$ chromosome is inactivated during the initial development of the foetus. One $X$ chromosome has everything needed for each cell .The genes on the inactivated $X$ chromosome are no longer used. This is a normal part of development. The selection of which $X$ gets inactivated in each cell is thought to be a random process. This is only a concern if one $X$ chromosome has an altered gene, for instance the abnormal factor VIII or IX gene in haemophilia. Males (XY) have only one copy of an X chromosome in each cell so lyonization does not occur on this $\mathrm{X}$ chromosome. Females $(\mathrm{XX})$ have two $\mathrm{X}$ chromosomes in each cell and one of them will be inactivated.

\section{Female with haemophilia}

It is possible for a carrier to have low factor VIII or IX level (haemophilia) due to lyonization. Approximately $20 \%$ of carriers of the gene causing severe haemophilia have low factor VIII or IX level and are categorised as having mild haemophilia. Rarely, a carrier may have severe haemophilia due to extreme lyonization. It is also possible for a girl to have severe haemophilia if her father is a person with haemophilia and her mother is a carrier. Up to one third of haemophilia is caused by new mutations where there is no family history.

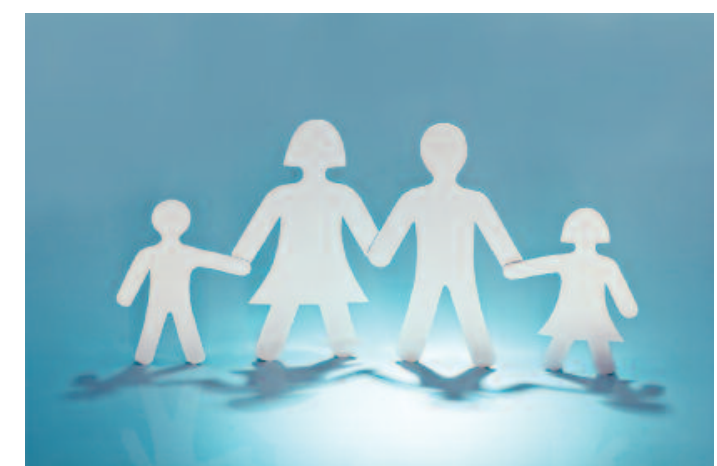




\section{Bleeding Disorders}

\section{Von Willebrand's Disease}

Von Willebrand's disease (vWD) is the most common type of bleeding disorder. It affects about $1 \%$ of the population. All types of vWD are inherited in an autosomal pattern (see How are Bleeding Disorders inherited on page 6). There are 3 types of vWD.

Type $\mathbf{1}$ is the most common. There is a reduced amount of von Willebrand factor (vWF) in the blood.

Type 2 is the next most common. The vWF protein is abnormal and does not work properly. Type 2 includes several sub-types.

Type $3 \mathrm{vWD}$ is the rarest and the most severe form. People with Type $3 \mathrm{vWD}$ have almost no vWF. As vWF transports Factor VIII in the bloodstream, people with Type 3 vWD have very low levels of Factor VIII as well.

\section{Platelet Function Disorders}

Platelet function disorders may affect as many as $1 \%$ of the population. The majority of these disorders are mild and many go undiagnosed. However, some types of platelet function disorders, such as Glanzmann's Thrombasthenia, are more serious. Depending on the type of platelet function disorder, platelets may not stick to the walls of damaged blood vessels or form a proper surface so that other blood factors can form a clot at the site of an injury. The congenital platelet function disorders have variable inheritance patterns.

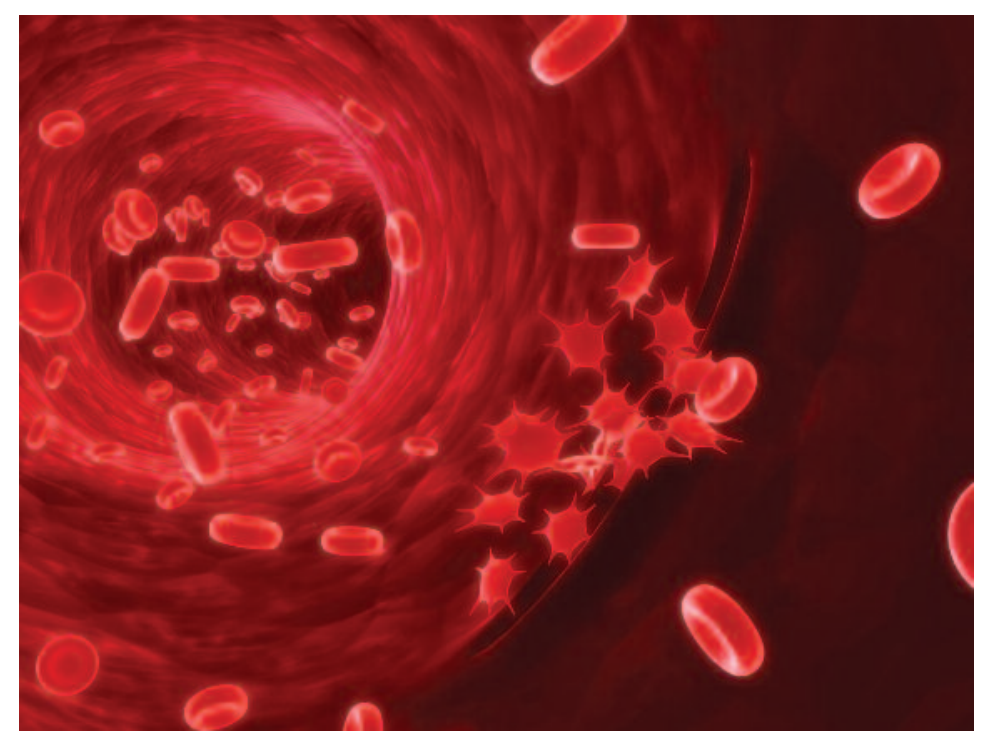




\section{Other clotting factor deficiencies}

There are a large number of other bleeding disorders caused by deficiencies of other clotting proteins in the blood. These are inherited in an autosomal recessive pattern.

\begin{tabular}{|l|l|l|l|}
\hline Factor & Other name & Incidence & Bleeding \\
\hline Factor I & Fbrinogen & in $1,000,000$ & Usually mild \\
\hline Factor II & Prothrombin & 1 in $1,000,000$ & Usually mild \\
\hline Factor V & Para haemophilia & 1 in $1,000,000$ & Usually mild \\
\hline $\begin{array}{l}\text { Combined FV \& } \\
\text { FVIII }\end{array}$ & & 1 in $1,000,000$ & Usually mild \\
\hline Factor VII & & 1 in 500,000 & $\begin{array}{l}\text { Severe when factor levels are below } \\
1 \%\end{array}$ \\
\hline Factor X & Stuart-Prower & 1 in 500,000 & $\begin{array}{l}\text { Moderate to severe when Factor X } \\
\text { levels are below } 10 \%\end{array}$ \\
\hline Factor XI & Haemophilia C & 1 in 100,000 & $\begin{array}{l}\text { Mild to moderate when Factor XI } \\
\text { levels are below } 15 \%\end{array}$ \\
\hline Factor XII & & 1 in 3,000,000 & $\begin{array}{l}\text { Severe when factor levels are below } \\
1 \% \text { below }\end{array}$ \\
\hline
\end{tabular}

[These rare bleeding disorders will be explained more comprehensively in the I.H.S. booklet Rare Bleeding Disorders.]

\section{Haemophilia and Symptomatic Carriers}

\section{Haemophilia}

Haemophilia A (Factor VIII deficiency) and Haemophilia B (Factor IX deficiency) are sex linked inherited bleeding disorders.

When haemophilia is passed along a family, the type and severity of haemophilia is always the same in the male with haemophilia. However, clotting factor levels in carriers are independent of the severity of the haemophilia in males and can vary from person to person because of lyonization. A carrier of a mild form of haemophilia can have the same factor levels as a carrier of the severe form of haemophilia. Within a family factor levels in related carriers can be very different, ranging from very low to normal.

Those with clotting factor levels from $5-40 \%$ are diagnosed as having mild haemophilia, 1 - 5\% moderate haemophilia and less than $1 \%$ severe haemophilia. Females may experience the same problems as males with the same factor levels. The majority of carriers have clotting factor level between $0.4 \mathrm{iu} / \mathrm{ml}$ and $0.7 \mathrm{iu} / \mathrm{ml}$ and do not bleed. A carrier who has a factor level less than $0.4 \mathrm{iu} / \mathrm{ml}$ can be considered to have mild haemophilia or to be a "symptomatic carrier". All carriers (possible and obligate) should have factor VIII or IX level checked because of the increased risk of bleeding in carriers with low factor levels. 
Recent studies have shown that women with clotting factor levels as high as $0.6 \mathrm{iu} / \mathrm{ml}$ can have abnormal bleeding problems, including, but not restricted to gynaecological and obstetric bleeding. Up to $57 \%$ of carriers do have gynaecological problems related to excessive menstrual bleeding which can vary from mild to severe.

\section{Symptomatic Carriers}

Symptomatic carriers are those with an increased bleeding tendency due to reduced clotting factor. The risk of bleeding is highest in those with the lowest clotting factor levels. Some of these bleeding symptoms include:

- Easy bruising.

- Prolonged bleeding from minor wounds.

- Bleeding from the nose (epistaxis).

- Prolonged bleeding after tooth extraction or surgery.

- Prolonged bleeding after trauma.

- Heavier and more prolonged bleeding during periods (menorrhagia)

- Increased risk of bleeding following delivery (post partum haemorrhage).

\section{Tests}

Factor VIII or Factor IX assay: This measures the amount of factor VIII or IX in the blood. It is important to know the factor VIII or IX level early in life as girls with low factor levels are at increased risk of bleeding. A girl with a normal factor level may still be a carrier of factor VIII or IX deficiency.

Factor VIII level can be affected by hormone levels (pregnancy, contraceptive pills, breast-feeding), by physical and mental stress and exercise. Factor IX levels are not affected by hormones.

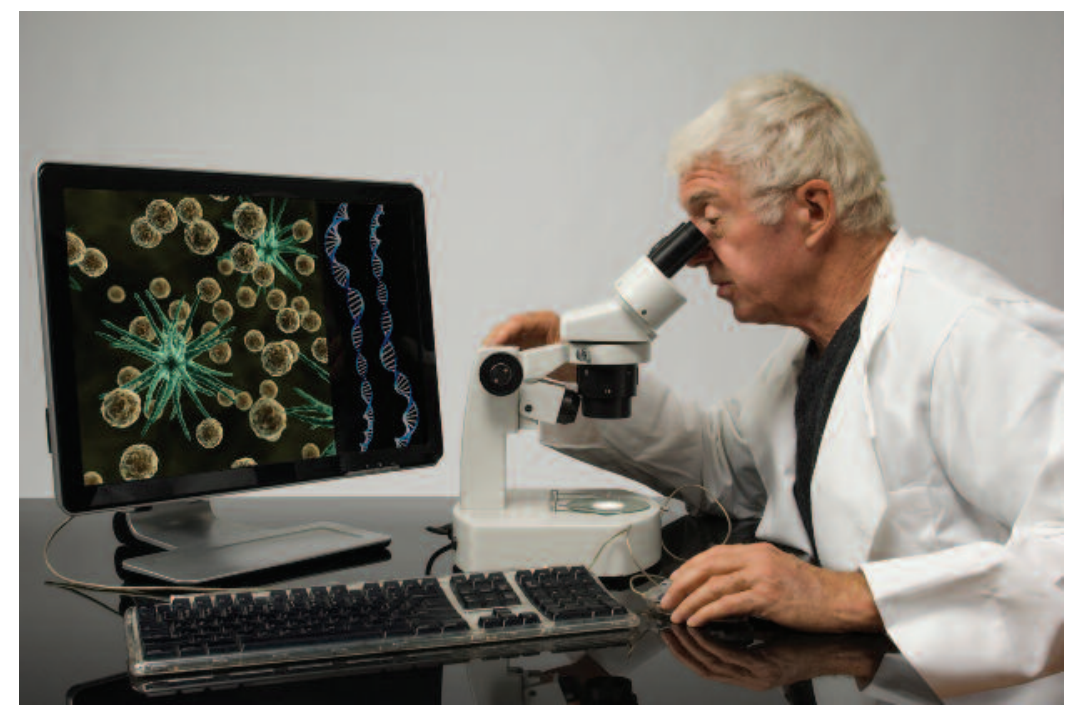




\section{Genetic analysis to determine carrier status}

There are a number of genetic tests that can be done to determine carrier status. These tests are complex. Results are more reliable if DNA from a family member with haemophilia is also available.

\section{Genetic testing in childhood versus genetic testing in adulthood}

In Ireland, the policy is that a possible carrier must be old enough to understand the implications of the test results before genetic testing is carried out. This is usually after 16 years of age. The sooner a girl is tested after this age, the more time she has to come to terms with being a carrier. It also prepares her for eventual decisions about pregnancy and childbirth.

There are some arguments against carrier testing by genetic analysis at a young age. It may affect the child's self-esteem or the family's perception of the child. Some families feel the only reason to know about carrier status is for family planning.

\section{Psychosocial issues}

People cope in different ways when they are faced with new information. This depends on age, reasons for seeking the test and on any previous experience they might have with the condition. Carriers can receive this diagnosis at a young age due to health problems, or as adults after the birth of a child with haemophilia in the family. A girl or woman can experience a wide range of emotions when she finds out that she's a carrier. She may be afraid of what it will mean for her, her relationships and any children she may have. She may feel a sense of loss that she is different from everyone else and may even fall into a pattern of denial and refuse to acknowledge the diagnosis. When a son is diagnosed with haemophilia and there is no family history, parents also have to deal with the possibility that his sisters are carriers. Parents may feel like this is a second blow. A person's decision to progress with carrier testing can affect the extended family. Genetic counsellors can provide suggestions on how to inform other at-risk female relatives such as sisters, daughters or nieces.

\section{Where?}

Call the National Centre for Hereditary Coagulation Disorders (NCHCD) at St. James's Hospital on 014162141 / 014162142 or Cork University Hospital on 021 4922278 for advice and an appointment.

Please also note:

- It is best if a member of your family with or carrying haemophilia has already had their genetic mutation identified.

- The Clinic is co-ordinated by a Clinical Nurse Specialist.

- A follow up appointment is sent when results are available.

- A confirmatory sample is requested when attending for results of initial sample.

- $\quad$ Results may take some time especially if the genetic mutation has not been previously identified in your family. 


\section{Gynaecological Problems}

\section{Menorrhagia}

Menorrhagia or heavy menstrual bleeding is the most common symptom for women who have a bleeding disorder. It is defined as bleeding that lasts for more than 7 days or results in the loss of more than $80 \mathrm{mls}$ of blood per menstrual cycle.

In addition to heavy menstrual loss, women with bleeding disorders suffer from prolonged bleeding (more than seven days), excessive passage of large blood clots and flooding during menstruation. Adolescent girls and post-menopausal women may suffer the most, as menstrual cycles are often anovulatory (i.e. no egg is released) during these reproductive stages. This leads to irregular shedding of the endometrium (lining of the womb) and predisposes to increased and prolonged menstrual bleeding.

Perimenopausal women are also more likely to have pelvic disease, such as fibroids and endometriosis, which increase the risk of bleeding.

It can be hard for any woman to tell if menstrual bleeding is unusually heavy compared to others. In a woman with a bleeding disorder, comparison to other family members can be misleading as they too may have the same bleeding disorder resulting in heavy menstrual bleeding. Nobody sees it as special or, if they do, they say, "All the women in our family bleed a lot during their periods."

The following guidelines should alert a woman to a potential problem with excessive menstrual bleeding:

- $\quad$ Flow which lasts longer than 7 days.

- $\quad$ Flow soaking one pad in less than 2 hours.

- Unpredictable bleeding.

- $\quad$ Menstrual bleeding which affects quality of life.

- $\quad$ Periods heavy enough to cause anaemia.

\section{Management of Menorrhagia in Women with Bleeding Disorders}

Since abnormal bleeding may be a sign of a gynaecological problem or a symptom of a bleeding disorder, a full gynaecological assessment is recommended prior to treatment of Menorrhagia.

With the exception of drugs such as Ponstan (NSAID) which affect platelet function, other gynaecological treatment options may be suitable for patients with bleeding disorders depending on the woman's age, gynaecological condition and reproductive plans. 


\section{Treatment}

\section{Combined Hormonal Contraceptives}

Combined hormonal contraceptives reduce menstrual blood loss by thinning the endometrium and possibly increasing factor VIII and von Willebrand factor levels. Combined hormonal contraceptives currently available include combined oral contraceptive pill (COC), transdermal contraceptive patches, and vaginal rings. They provide reliable birth control and cycle control and reduce dysmenorrhoea and other menstrual complaints. In women with bleeding disorders they have an added advantage of controlling ovulation bleeding and midcycle pain. Continuous use of these therapies (rather than the traditional 21 day course) is safe and can be used to control timing and frequency of menstruation as well as menstruation associated symptoms. This can be very useful for women with severe menstrual problems.

Most women who use combined hormonal contraceptives have none or very few side effects. Serious side effects of hormonal contraceptives include high blood pressure, liver abnormalities and clots. Women with bleeding disorders, however, may have a low inherited risk of clotting. Side effects that some women have are nausea, headaches, dizziness, breast tenderness and mood changes. Some of these side effects improve over the first 3 months. If the side effects continue the doctor may prescribe a different brand of hormonal contraceptive.

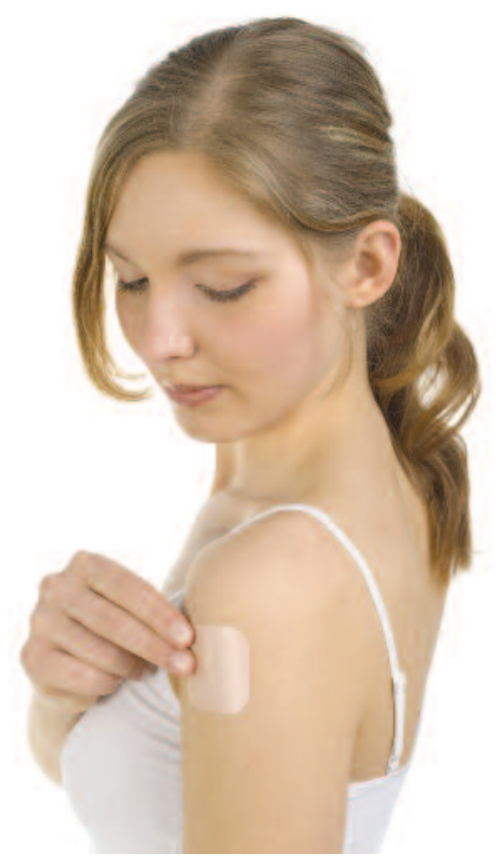




\section{Levonorgestrel intrauterine system}

Levonorgestrel intrauterine system (LNG-IUS, Mirena®) is the most effective medical treatment for menorrhagia and has been shown to be useful for reducing menstrual blood loss in women with bleeding disorders. It is also an effective and reversible method of contraception making it an ideal treatment for women with menorrhagia who want to preserve their fertility. The licensed duration of use in Ireland is 5 years i.e. once inserted it may stay in place for 5 years. The main problem is irregular bleeding or spotting, especially within the first 6 months. In women with bleeding disorders, there is a potential risk of bleeding at the time of insertion and preventative treatment with a haemostatic agent may be required.

\section{Oral progestogens}

Oral progestogens such as medroxyprogesterone acetate and norethisterone are recommended treatments for menorrhagia when used as a 21 day course (days 5-26). Side effects include fatigue, mood changes, weight gain, bloating, depression, and irregular bleeding. In high doses, oral progestogens can be used with DDAVP or clotting factor to treat acute menorrhagia in women with bleeding disorders.

\section{Progestin only contraceptives}

Progestin only contraceptive such as Depo-Provera (medroxyprogesterone acetate) injections, progestin-only pills, and the Implanon implant also reduce endometrial thickening and may reduce menstrual blood loss or stop menstruation. They are associated with a high rate of irregular bleeding and spotting. Insertion of the Implanon implant may also cause bleeding in women with bleeding disorders and preventative treatment with a haemostatic agent may be required.

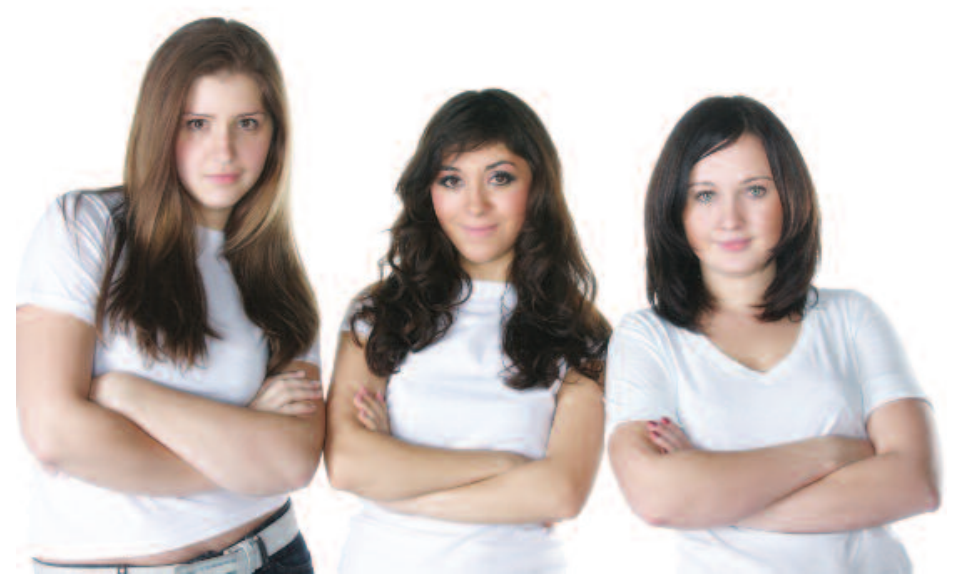




\section{Gonadotropin relasing hormone $(\mathrm{GnRH})$ analogues}

These drugs stop ovulation and are effective for reducing menstrual flow and duration. Side effects due to reduced oestrogen include hot flushes and loss of bone density (which is reversible). GnRH analogues may be an alternative option to surgery for young women with resistant menorrhagia or severe bleeding disorders. If used for more than six months, hormone replacement therapy should be added to counteract low oestrogen levels.

\section{Haemostatic therapy}

Haemostatic therapy may be effective in controlling Menorrhagia in women with bleeding disorders. Haemostatic agents constitute the main treatment option for women who are trying to conceive. They are also used in women who do not wish to get pregnant, either alone or in combination with hormonal therapy. Haemostatic therapies include DDAVP (1-desamino-8-D-arginine vasopressin), tranexamic acid and coagulation factor concentrates.

Oral tranexamic acid also known as Cyclokapron (1g, 3-4 times a day during the menstrual period) is usually well tolerated but side effects include nausea, headache, and diarrhoea. Tranexamic acid stabilises a clot once it has formed by stopping the activity of an enzyme, called plasmin, which dissolves blood clots.

\section{[Note: A person with urinary tract bleeding (blood in the urine) should not take this drug.]}

DDAVP (Desmopressin) can be given by intravenous injection or intranasally as a spray. For management of menorrhagia, it is usually administered as a nasal spray (150-300mcg daily for a maximum of 3-4 days, usually during days with the heaviest blood flow). Side effects include fast heart rate, flushing and headache. There is also a small risk of reduced sodium (salt) level and fluid retention. Therefore, fluid restriction during treatment is essential. If a person has a very bad headache or has not been able to urinate 24 hours after taking DDAVP, they should contact the Haemophilia Treatment Centre or Accident and Emergency for advice. In the elderly and in people with cardiovascular disease, Desmopressin can cause more serious side effects and may not be recommended.

Both tranexamic acid and DDAVP alone or in combination may be effective in controlling menorrhagia in women with bleeding disorders.

Regular prophylaxis with clotting factor replacement may be required to control menorrhagia in some women with severe factor deficiencies not responding to other treatments. These include plasma-derived factor concentrate or recombinant (genetically engineered) concentrate. All plasma used is screened for blood-borne viruses such as HIV, Hepatitis B and Hepatitis C and treated to inactivate any known viruses. 


\section{Surgical treatment}

Surgery may be required in the presence of pelvic disease and for women who do not tolerate medical treatment or in whom this is unsuccessful. Women with inherited bleeding disorders are more likely to have peri-operative and/or delayed (7-10 days later) bleeding, even with relatively minor procedures such as hysteroscopy and biopsy. Therefore, any surgical intervention should be performed in a centre with available laboratory support and an experienced haematologist. Prophylactic treatment may be required pre-operatively to reduce the risk of excessive bleeding. Surgical options include hysterectomy and endometrial ablation.

These procedures eliminate the possibility of future pregnancy and are only for women who do not want to have future pregnancy.

\section{Hysterectomy}

Hysterectomy is the surgical removal of the uterus, not including the removal of the ovaries and fallopian tubes. Haemorrhage is the most common complication. Others include genitourinary complications, infection, and poor wound healing. A lengthy post operative recovery period is required. Long term complications include early ovarian failure (premature menopause) and urinary and sexual problems. Peri-operative bleeding complications are of specific concern in women with bleeding disorders.

Therefore, hysterectomy should not be the first line treatment but used only when other treatments fail or when pelvic disease indicates its use in women who no longer wish to retain fertility.

\section{Endometrial ablation}

Endometrial ablation techniques are now widely used as an alternative to hysterectomy. They may reduce menstrual blood loss in women with bleeding disorders. Endometrial ablation removes a thin layer of the lining of the uterus and stops the menstrual flow in many women. In some women, menstrual bleeding does not stop but is reduced to normal or lighter levels.

These procedures have a shorter operating time, recovery time, and complication rate when compared to hysterectomy.

Possible complications are:

- $\quad$ Cramping, like menstrual cramps for 1-2 days

- $\quad$ Thin, watery discharge mixed with blood, which can last a few weeks

- $\quad$ Frequent urination for 24 hours

- $\quad$ Nausea 


\section{Other gynaecological conditions}

\section{Dysmenorrhoea (painful period)}

Women with bleeding disorders and carriers more commonly suffer from period pain. Usual treatments include non steroidal anti- inflammatory drugs such as Nurofen but these should be avoided in women with bleeding disorders because of their anti platelet activity. Alternative painkillers such as paracetamol and codeine based products may be used. The combined oral contraceptives may also help reduce period pain as may an intrauterine system releasing the hormone levonorgestrel (Mirena IUD) (see Hormonal therapy).

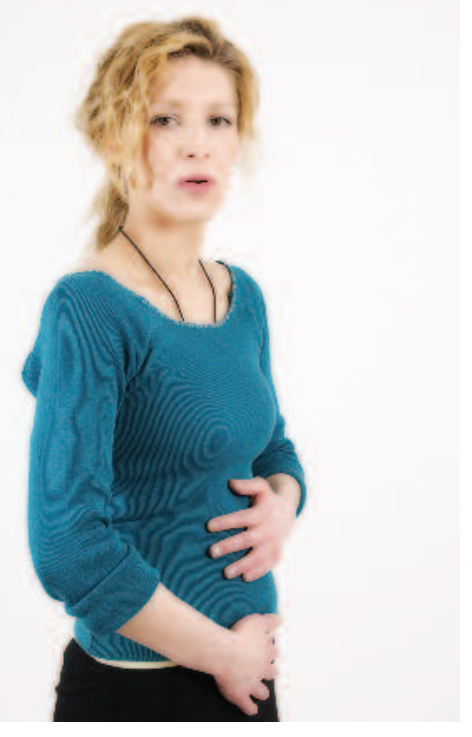

Haemorrhagic ovarian cysts

When a woman ovulates, a small amount of bleeding may occur with rupture of the egg follicle when the egg is released from the ovary. This may be associated with abdominal and pelvic pain. Women with bleeding disorders are more likely to have significant bleeding at ovulation with resulting pain, haemorrhagic ovarian cysts or even bleeding into the abdominal and pelvic cavity.

Although these gynaecological complications can be treated surgically, non surgical management with the use of appropriate clotting agents (tranexamic acid, DDAVP and coagulation factor replacement) is advisable in women with bleeding disorders. Combined oral contraceptives suppress ovulation and have been successfully used to prevent recurrences. 


\section{Endometriosis and other gynaecological conditions}

Endometriosis is a painful condition in which endometrial tissue, the tissue which lines the uterus, implants in the pelvis and organs outside of the uterus. There is no strong evidence that women with bleeding disorders are more likely to develop endometriosis, fibroids, polyps of the uterus or endometrial hyperplasia (excessive growth of the lining of the uterus) but in a survey of 102 women with vWD by the US Centers for Disease Control, these gynaecological problems were more likely to be reported by women with vWD than women without vWD. Since most of these gynaecological conditions often present with bleeding, women with bleeding disorders are more likely to develop symptoms and therefore to be diagnosed.

\section{Menopause}

Menopause is the time in a woman's life when menstrual periods permanently stop. Peri-menopause is a 3 to 10 -year period before natural menopause, when hormones are "in transition." Symptoms of peri-menopause include heavy menstrual bleeding, irregular bleeding and spotting. Since there are other medical reasons for heavy bleeding, and women with bleeding disorders are at the same risk for these problems as other women, a full medical investigation should be done to eliminate other causes of bleeding. As in all women, the cause of the abnormal menstrual bleeding needs to be determined before any treatment is offered. If the bleeding is caused by lack of ovulation, hormone replacement therapy (HRT) will usually control the problem. However, if a woman is already using HRT, she may need to discuss other options with her gynaecologist and her haematologist. She may require other forms of treatment such as endometrial ablation or a hysterectomy.

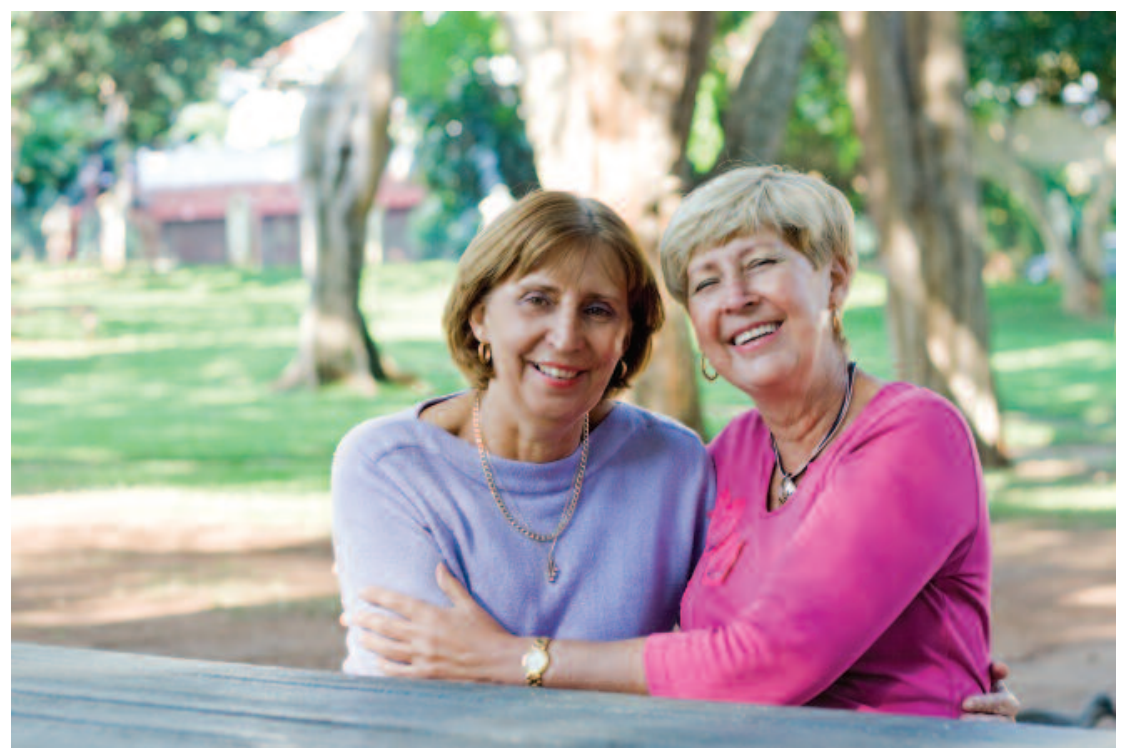


It is important that women maintain a strong relationship with their gynaecologist even after childbearing years in order to anticipate the combined issues of menopause and bleeding disorders.

\section{Acute adolescent menorrhagia}

Menstrual bleeding can be especially heavy at the time of a girl's first period. Girls and adolescents with known bleeding disorders should be counselled prior to their first period and have a plan for the possibility of acute, severe menorrhagia, which could occur with their first or any subsequent menstrual period. The plan should be made by the gynaecologist and haematologist, in conjunction with the patient and her family. Because of the increased risk of transfusion, girls and adolescents should be immunized against Hepatitis A and Hepatitis B. Management is beyond the scope of this text.

\section{Other types of bleeding}

Depending on the bleeding disorder or levels of factor VIII or IX in carriers, women may experience nosebleeds, gum bleeds, bruising and bleeding after trauma. Joint and muscle bleeds can very rarely occur. Women with bleeding disorders and carriers with low levels are at risk for developing bleeding after surgery, dental extraction and medical diagnostic interventions. Therefore specialist advice should be sought from the haemophilia treatment centre prior to such interventions.

\section{Treatment Options for Other Types of Bleeding}

Minor bleeding episodes such as nose bleeds and bruises often do not require medical treatment. Minor bleeds can often be controlled with R.I.C.E (Rest, Ice, Compression and Elevation). However, sometimes medical treatment is necessary. The type of treatment depends on the type of bleeding disorder and the type of bleeding.

Tranexamic acid, See page 17

DDAVP (Desmopressin), See page 17

Coagulation Factor Concentrate Replacement Therapy, See page 17

\section{Fibrin Glue}

In the coagulation process, the final clot is made up of fibrin. Fibrin can be applied directly to the site of bleeding. It is especially useful in tooth extractions and surgery. Over a period of 2 to 4 weeks the fibrin is absorbed by the body as healing progresses. 


\section{Pregnancy in Women with Bleeding Disorders}

\section{Preconception counselling}

Women suspected of having a bleeding disorder or of being a carrier should have diagnostic testing before getting pregnant to allow for appropriate preconception counselling and early pregnancy management. This is especially important for women with severe bleeding disorders or those who could potentially carry a severely affected baby, such as carriers of severe haemophilia.

\section{Preconception counselling has two benefits:}

1. It provides women and their family with adequate information on the genetic implications of their disorder, the available reproductive choices and options for prenatal diagnosis.

2. It allows planning for pregnancy and establishing how and where the pregnancy can be best managed. Other aspects of preconception care include immunization against hepatitis $\mathrm{A}$ and $\mathrm{B}$ for those likely to require blood transfusion and general advice such as Folic Acid supplementation. A DDAVP trial can also be carried out to assess response to this particular treatment option.

Psychological support should be available during all aspects of counselling. Women should also be offered the opportunity to speak with a paediatric haematologist regarding the care of a potentially affected child.

\section{Prenatal diagnosis (PND)}

PND is primarily considered in carriers of haemophilia because of the severity of the disorder in male offspring and because many affected families are already aware of the genetic defect. For each pregnancy in carriers of haemophilia, there is a $50 \%$ chance that a male child will have haemophilia and a $50 \%$ chance that a female child will be a carrier. In other bleeding disorders, prenatal diagnosis is considered only when the foetus is at risk of being affected with severe forms of the disorder. Since most bleeding disorders are autosomal recessive, this risk is more common in families and cultures with high rates of intermarriage.

\section{Foetal sex determination}

Foetal sex determination can be useful in the management of pregnancies at risk of haemophilia. This can be reassuring to the parents when the foetus is female, and invasive testing can then be avoided. It will also enable the management plan for labour and delivery to be refined to avoid using instruments and invasive monitoring techniques in male foetuses, which have a $50 \%$ chance of being affected. Foetal sex may be determined in two ways:

\section{Maternal blood test}

The sex of the foetus can be determined from foetal DNA which can be extracted from a sample of the mother's blood at approximately 9 weeks gestation. 


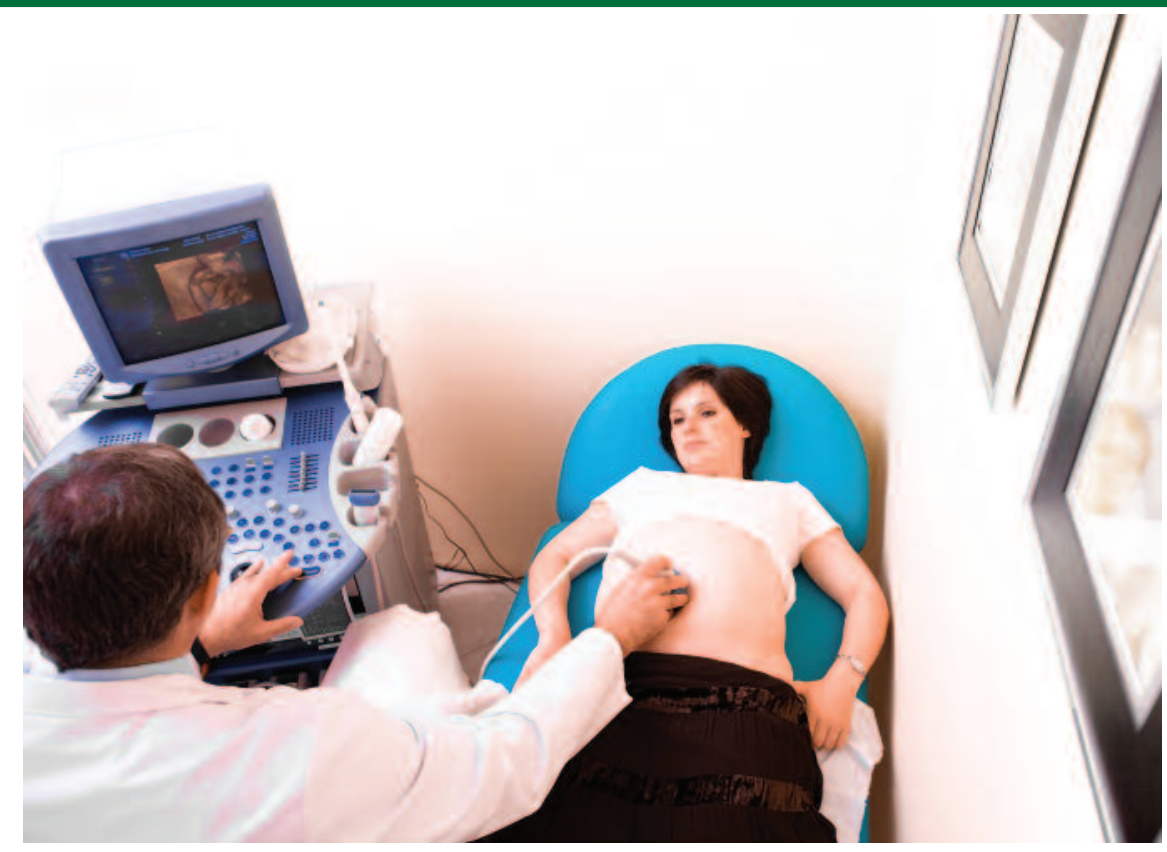

\section{Ultrasound}

Foetal sexing can be performed easily by ultrasound from the second trimester.

Definitive prenatal diagnosis can only be obtained with invasive tests in pregnancy, such as chorionic villus sampling (CVS), amniocentesis, and cordocentesis (see below). These procedures are associated with a risk of miscarriage / foetal loss. The causative genetic mutation must be known prior to CVS and amniocentesis.

CVS is the method most widely used today for prenatal diagnosis of inherited bleeding disorders. It is performed at 11-14 weeks gestation under ultrasound guidance. It has the advantage of earlier diagnosis compared to amniocentesis, which is performed at 15-20 weeks gestation. Both are associated with an approximately $1 \%$ risk of miscarriage. See glossary for further information on chorionic villus sampling and amniocentesis.

Cordocentesis (ultrasound guided foetal blood sampling) is performed at around 18-20 weeks gestation to obtain foetal blood for a clotting factor assay. The risk of miscarriage is higher with this procedure compared to amniocentesis or CVS. It is rarely performed today and may be an option for cases in which the causative genetic mutation cannot be identified. Women at risk for severe bleeding should receive prophylaxis (treatment) to normalise clotting prior to any invasive procedure. 


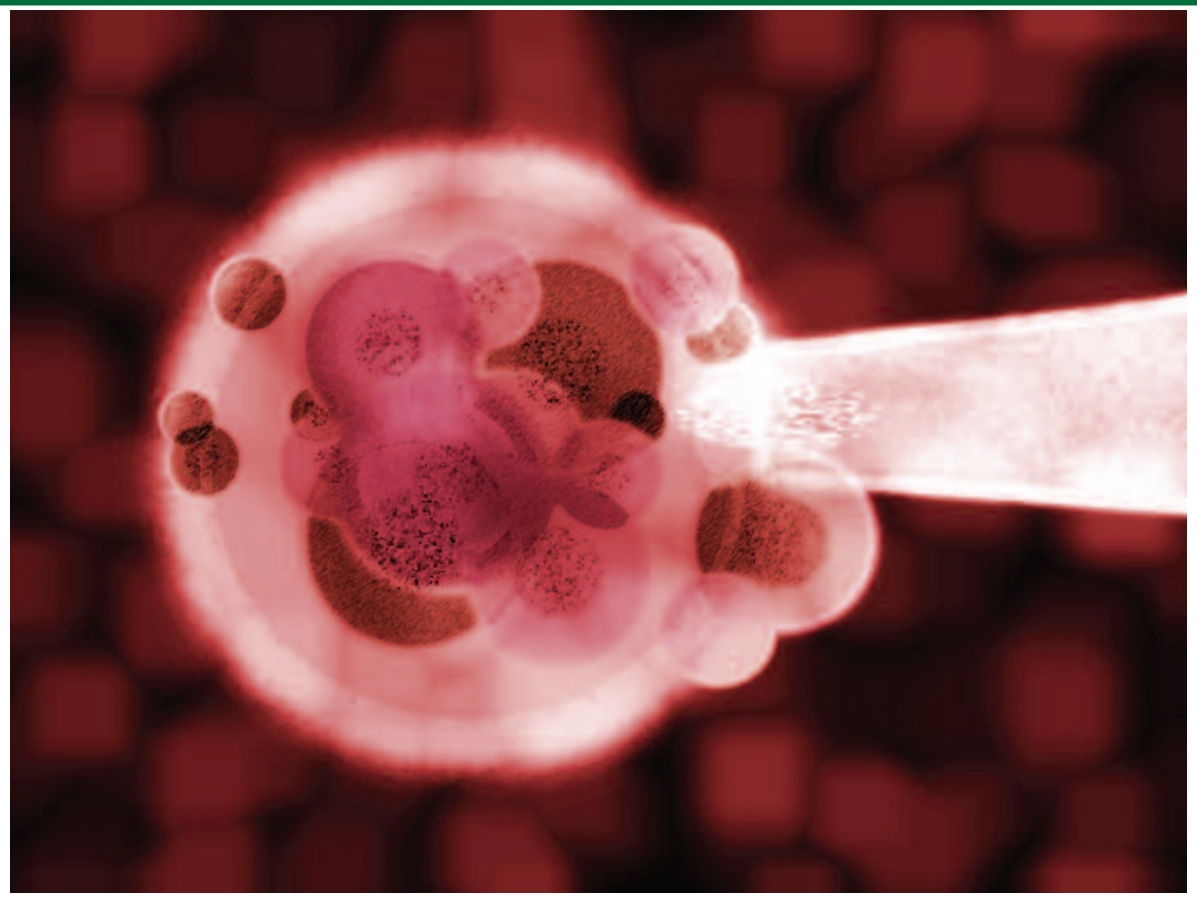

Pre-implantation genetic diagnosis

Pre-implantation genetic diagnosis is a relatively new technique. Embryos created using in vitro fertilization (IVF) are tested to identify those that are unaffected by the bleeding disorder and these are then selectively transferred to the uterus. There have been reports of its success recently in carriers of haemophilia. This method will likely become a realistic option for some individual cases in the near future. However, further evidence on its efficacy and safety is still required. The cost and stress associated with IVF also need to be considered. Pre-implantation genetic diagnosis is not available in Ireland.

Access to prenatal diagnosis in the UK is available through the NCHCD, at St. James's Hospital, in Dublin, Cork University Hospital and the National Centre for Medical Genetics at Our Lady's Children's Hospital, Crumlin.

\section{Antenatal Management}

Normal pregnancy causes increased concentrations of several coagulation factors including VIII, VWF and fibrinogen. Factor IX levels do not usually change significantly. These changes contribute to improved blood coagulation in women with bleeding disorders. Despite this improvement, however, women with bleeding disorders often do not achieve the same levels of clotting factors that other women do, and, therefore, are still at an increased risk of bleeding complications. 


\section{Miscarriage/ Pregnancy Complications}

There is no evidence of a higher rate of miscarriage in carriers and women with other bleeding disorders than in the general population. However women with certain rare factor deficiencies (such as factor XIII deficiency and fibrinogen deficiency) may be at greater risk of miscarriage and placental abruption (a premature separation of the placenta from the uterus that disrupts the flow of blood and oxygen to the foetus). Therefore, these women may require factor replacement throughout the pregnancy to prevent these complications.

Approximately $20 \%$ of all pregnancies are complicated by at least one bleeding episode, so bleeding in pregnancy may not be due to an underlying bleeding disorder. Obstetric causes should not be overlooked.

\section{Management of labour and delivery}

The management of childbirth will depend on the needs of the mother and her potentially affected infant at the time of delivery. Women at risk of bleeding should ideally be referred for antenatal care and delivery to a centre, where in addition to specialist high risk obstetrics, there is a haemophilia treatment centre or a haematologist with expertise in coagulation. Laboratory, pharmacy, and blood bank support is essential.

If the mother is not near a haemophilia treatment centre, the local hospital and medical team should be prepared beforehand for the woman's and for the baby's possible needs. Making decisions beforehand and having a written plan (birth plan) at home and at the hospital is important.

Prior to delivery, all women with bleeding disorders should have the opportunity to meet with an anaesthetist. There is no consensus on the factor levels that are safe for epidural, but if levels are at least $0.5 \mathrm{iu} / \mathrm{ml}(50 \%)$ and the rest of the coagulation studies are normal, epidural may be considered safe.

It is acceptable to use third trimester levels to devise an appropriate plan for delivery. If the factor level is low in the third trimester, prophylactic treatment may be necessary to prevent bleeding.

Desmopression (DDAVP) may be used to raise factor VIII and von Willebrand factor levels in carriers of haemophilia A and women with VWD prior to invasive procedures. It is generally thought to be safe for mother and foetus, but care must be taken in its administration at the time of childbirth. It should be used with caution if the mother has received intravenous fluids due to possible complications associated with fluid retention.

The foetus is also at risk of bleeding complications during the process of birth. Invasive monitoring techniques (e.g. fetal scalp electrode, fetal scalp blood sampling) and instrumental deliveries (ventouse, midcavity or rotational forceps) should be avoided in pregnancies with potentially affected fetuses, as serious head bleeding may result from these procedures. 
Normal vaginal delivery is not contraindicated in these pregnancies, but prolonged labour should be avoided and delivery achieved by the least traumatic method. Although caesarean section may not completely eliminate the risk of serious bleeding complications in the newborn baby, the early recourse to caesarean section should be considered to minimize the risk of neonatal bleeding complications.

Low forceps delivery may be considered less traumatic than caesarean section when the head is deeply engaged in the pelvis and an easy delivery is anticipated. Delivery in these cases should be performed by an experienced obstetrician.

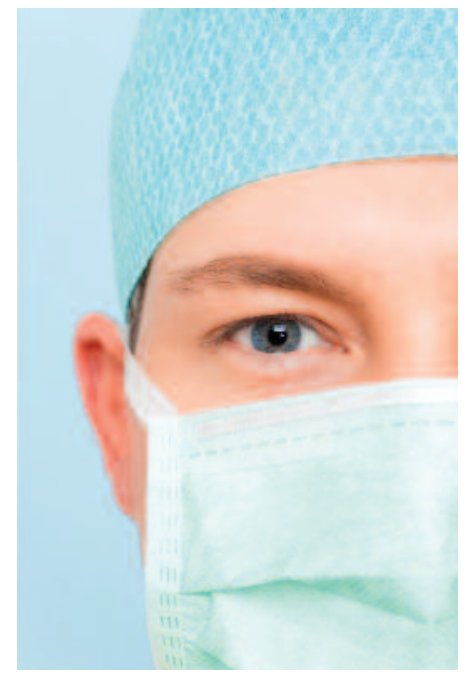

Factor levels should be measured on a cord blood sample. A cord blood sample should be collected from newborns at risk of moderate or severe inherited bleeding disorders to assess coagulation status and clotting factor levels. This enables the early identification and management of newborns at risk of bleeding complications.

When assessing neonatal clotting factor levels, it should be appreciated that the levels of vitamin K dependent factors (FII, FVII, FIX, and FX), correlate with gestational age due to liver immaturity and reach adult levels at six months of age. It is therefore not reliable to diagnose mild forms of inherited bleeding disorders at birth. Haemophilia A (FVIII deficiency), however, can be diagnosed at birth.

Transcranial ultrasound (through the fontanelle) should be done urgently on all newborns with possible bleeding disorder if delivery is traumatic or if there are signs suggestive of bleeding into the brain. Treatment with clotting factor concentrate may be necessary in such cases. 


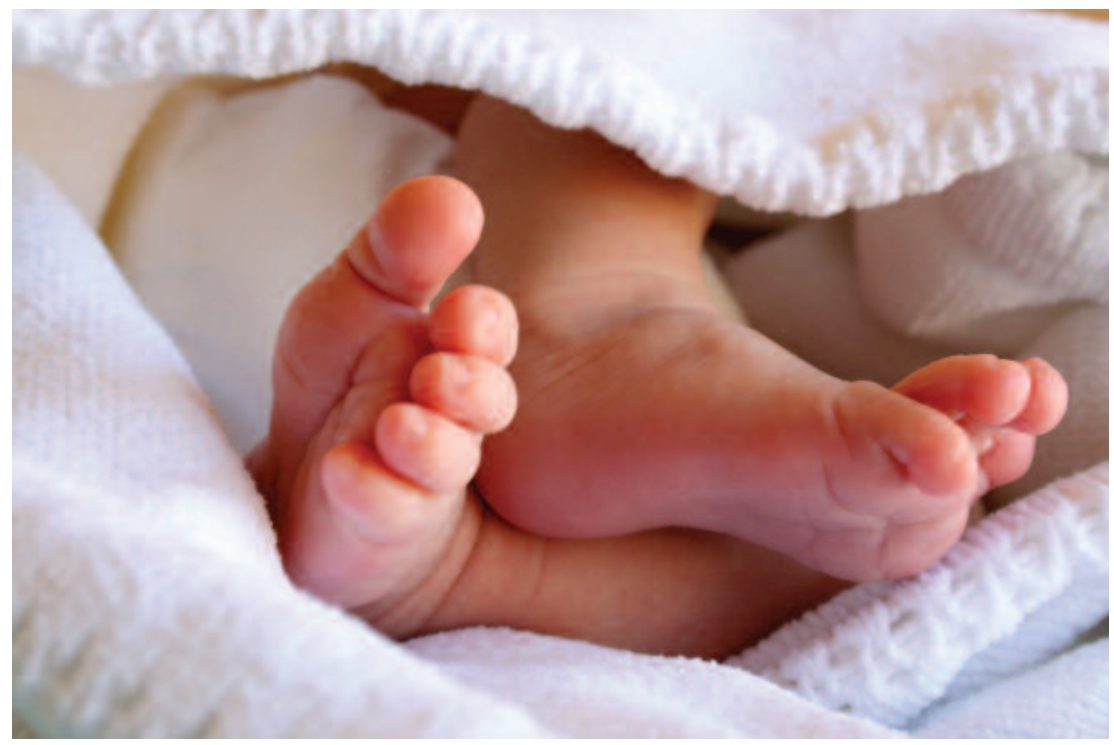

All infants with bleeding disorders should have a cranial ultrasound before discharge. Vitamin K should be administered by the oral and not intramuscular route. Intramuscular injections should be avoided in newborns at risk until the coagulation status is known. BCG can be administered as it is given into the skin.

Heel prick can be performed for Guthrie card analysis (screening for inherited disorders such as phenylketonuria (underactive thyroid)). Pressure should be applied for five minutes and the site should be closely observed for 24 hours. If the factor level is reduced then the child should be referred to the Paediatric Haematologist on call in Our Lady's Children's Hospital, Crumlin or Cork University Hospital.

Any surgical procedures (e.g. circumcision) should be delayed until the coagulation status of the newborn baby is known.

\section{Postpartum management}

The most common causes of post partum haemorrhage $(\mathrm{PPH})$ are uterine atony (inefficient uterine contractility), retained placenta or placenta pieces, and genital tract trauma. However, coagulation disorders are also a recognised cause of $\mathrm{PPH}$. After the delivery, the elevated coagulation factors return to pre-pregnancy levels within 14 to 21 days of delivery. Therefore, the main risk of bleeding is after miscarriage or delivery. PPH may occur up to six weeks post delivery. Women with bleeding disorders, especially those with severe disorders, are at risk of primary and secondary $\mathrm{PPH}$.

Primary PPH is blood loss or more than $500 \mathrm{~mL}$ in the first 24 hours after delivery. 


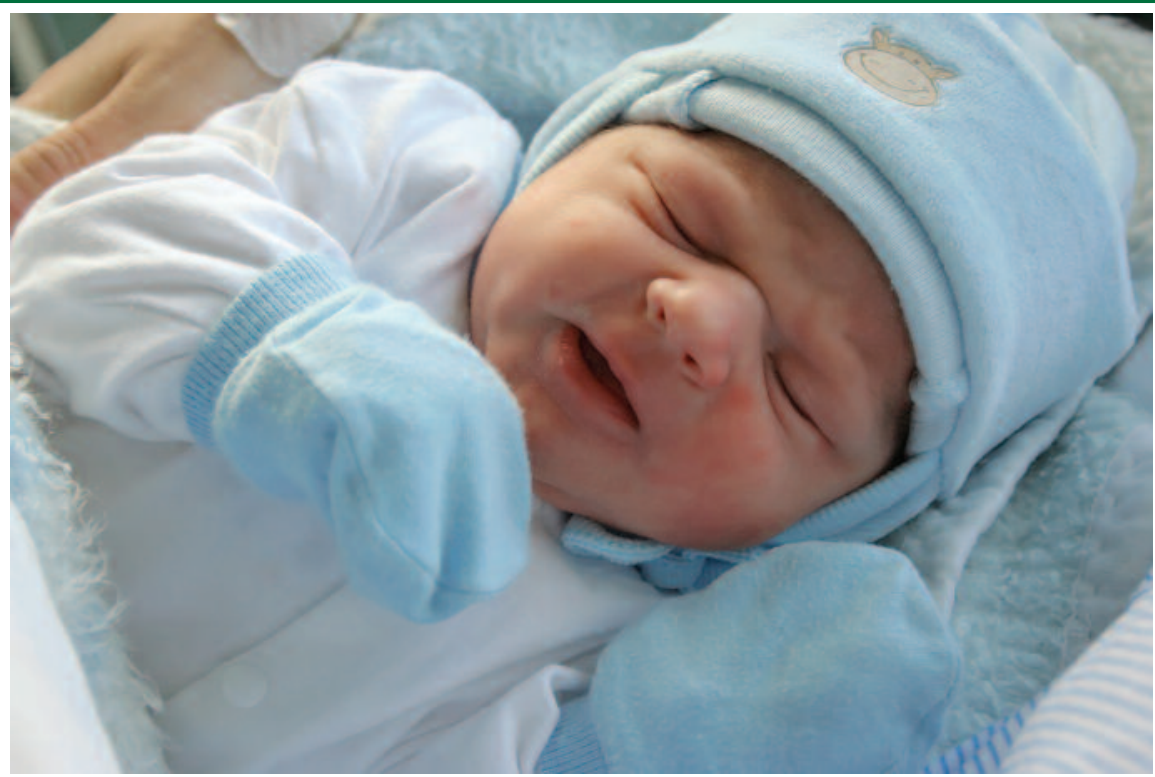

Secondary PPH is excessive bleeding occurring between 24 hours and six weeks post delivery.

Perineal/vaginal hematomas are rare complications of vaginal birth, but are also more likely to occur in women with bleeding disorders, especially after operative vaginal deliveries.

There may also be obstetric risk factors and causes of PPH in women with inherited bleeding disorders. Management of PPH in women with bleeding disorders requires close collaboration between haematologist, obstetricians and anaesthetists.

\section{Reducing the risk of PPH}

Prophylactic replacement therapy is recommended to cover labour, delivery, and the immediate postpartum period (at least three to four days for vaginal delivery and five to seven days for caesarean section) in women with low factor levels or inherited bleeding disorders. Recombinant products, if available, are the products of choice.

As the pregnancy-induced increase in coagulation factor return to pre-pregnancy levels women with bleeding disorders are particularly vulnerable to secondary postpartum haemorrhage. Oral tranexamic acid or combined oral contraceptive pills can be used for the prevention and management of secondary PPH. 


\section{Breast Feeding}

Breastfeeding increases factor VIII and von Willebrand factor levels in response to pregnancy hormones. Women who breastfeed may maintain the high hormone levels they had during pregnancy. This protects them from bleeding in the weeks following delivery. Desmopressin or tranexamic acid is passed through breast milk. Women with certain types of bleeding disorders can have bleeding problems postpartum whether or not they breast feed as they do not respond to pregnancy hormones.

\section{Conclusion}

It is vitally important that women with bleeding disorders understand their condition, and the potential impact it may have on them during menstruation, pregnancy, menopause and surgery. We hope this guide is of assistance to you in developing that knowledge. 


\section{GLOSSARY}

\section{Chorionic villas sampling (CVS)}

The chorion is a membrane that surrounds the developing foetus. It is located outside of the amniotic membrane and originates from the same cells as the developing baby. The sample may be taken either by the vaginal or abdominal route, depending on where the placenta is located. Vaginal CVS is similar to a smear. While an ultrasound is being done on the abdomen to locate the foetus, a speculum is inserted into the vagina. A fine tube is then passed through the cervix and guided to where the placenta is forming and a small portion is sampled. Results can take up to 3 weeks. CVS is avoided before 11 weeks because of reports of limb abnormalities occurring when carried out earlier.

\section{Amniocentesis}

Amniocentesis is done after 15.5 weeks. An ultrasound is performed to locate the placenta and to select a pocket of amniotic fluid. A thin needle is then inserted through the abdomen and into the uterus. A small amount of amniotic fluid is removed. This fluid contains cells that the foetus has shed. The risk for complications with the procedure is $0.5 \%$. Test results take 3 to 4 weeks if cells need to be grown before the test can be done.

\section{Autosomal}

A chromosome that is not a sex chromosome.

\section{Bleeding Disorder}

A disease in which the body is unable to form blood clots as quickly or as effectively as normal. The family of bleeding disorders includes von Willebrand disease, Haemophilia A, Haemophilia B, platelet function disorders, and a variety of rare factor deficiencies. Depending on the type of disorder, it may be inherited or acquired.

\section{Chromosomes}

A visible carrier of the genetic information.

\section{Concentrates}

Fractionated, freeze dried preparations of individual clotting factors or groups of factors. They provide convienent high-dose-to-volume material for the rapid treatment of bleeding episodes.

\section{Haemophilia}

A group of inherited bleeding disorders in which the ability of blood to clot is impaired.

\section{Haemophilia A}

Classic Haemophilia, due to deficiency of factor VIII, a blood factor necessary to normal clotting.

\section{Haemophilia B}

Haemophilia due to deficiency of coagulation factor IX, also known as Christmas disease.

\section{HTC}

Haemophilia treatment center. HTCs can provide Haemophilia patients with multidisciplinary care and have been shown to improve quality of life and reduce morbidity and mortality in patients with bleeding disorders.

\section{Infusion}

Injection of a solution into a vein in the body for medicinal or therapeutic purposes. 


\section{Intracranial}

Within the skull.

\section{Intramuscular}

Within the muscle.

\section{Intravenous}

Within a vein.

\section{Plasma derived}

Referring to biologic products made from human plasma.

\section{Platelets}

Fragments of the cells in bone marrow, that provide the necessary hormones and proteins for coagulation.

\section{Replacement Factor}

Coagulation factor products (either human plasma derived or recombinant) used for prophylaxis or treatment of bleeding episodes in patients with Haemophilia or related bleeding disorders.

\section{Recombinant}

Genetically engineered DNA. Recombinant technology uses genetic material to produce man-made blood products for medical use, reducing the risk of viruses from human blood products.

\section{Recessive}

In genetics, a hidden trait; a recessive gene produces its characteristics only when the recessive gene is present in both members of a corresponding pair of chromosomes.

\section{Spontaneous Bleed}

Bleeding episodes without obvious cause.

\section{Sex-linked}

Sex chromosomes are inherited in predictable patterns.

\section{von Willebrand Disease (vWD)}

A disease in which the von Willebrand factor in a patient's blood is deficient or defective.

There are three main types of VWD.

\section{von Willebrand Factor (vWF)}

The clotting protein that is deficient in VWD. VWF is either present at lower than normal levels or does not work properly.

\section{von Willebrand factor (VWF) concentrate}

A product made from human plasma for use in the treatment of VWD. 
Irish Haemophilia Society

First Floor, Cathedral Court, New Street, Dublin 8, Ireland.

Tel: 0035316579900

Fax: 0035316579901

Email: info@haemophilia.ie

Website: www.haemophilia.ie

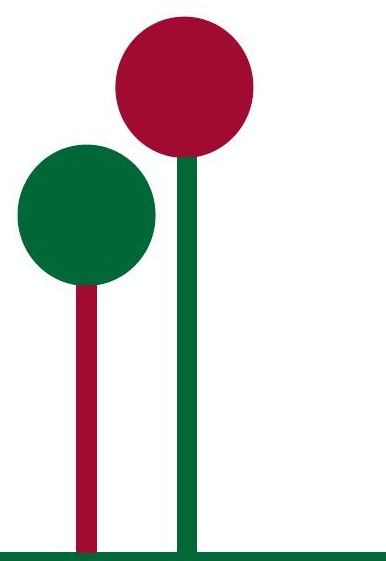

